\title{
Potencialidade para a autonomia em Unidades de Paisagem na área urbana de Paranaguá no litoral do Paraná
}

\author{
Potentiality for autonomy in Landscape Units in the urban area of Paranagua on the \\ coast of Paraná
}

Potencialidad para la autonomía en Unidades de Paisaje en el área urbana de Paranaguá en el litoral del Paraná

\section{Emerson Luis Tonetti}

Professor Doutor, IFPR-Paranaguá, Brasil emerson.tonetti@ifpr.edu.br

Patrícia Milla Gouvêa

Aluna de Mestrado CTS, IFPR-Paranaguá, Brasil. patricia.milla@yahoo.com.br

\section{Leandro Ângelo Pereira}

Professor Doutor, IFPR-Paranaguá, Brasil leandro.pereira@ifpr.edu.br 


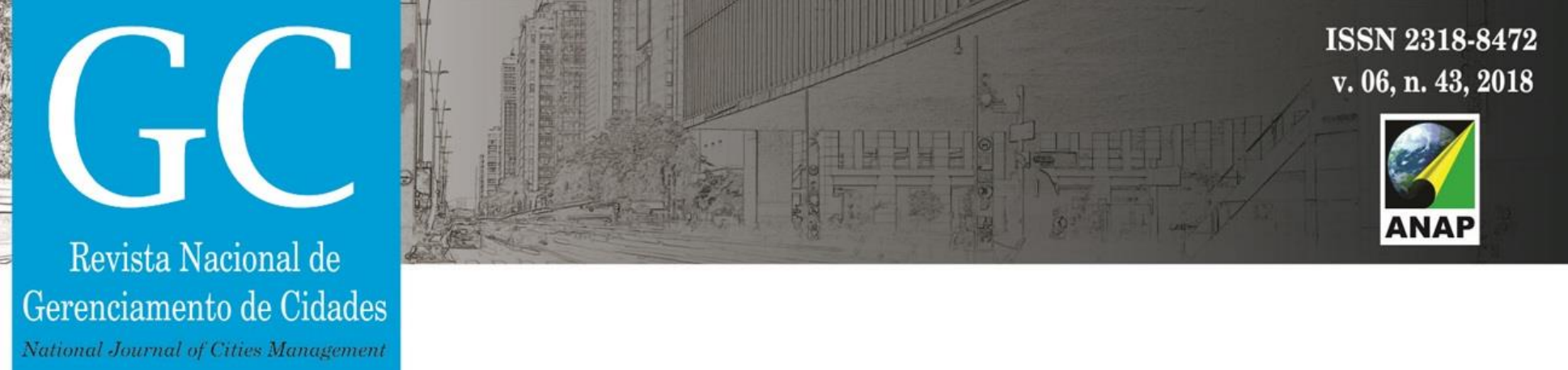

RESUMO

Na literatura existe intensa discussão sobre as vantagens e desvantagens do aumento da densidade populacional e das edificações, ou seja, da compactação para a sustentabilidade das regiões urbanas. A teoria da Cidade Compacta indica que quão maior a autonomia de unidades urbanas, maior será sua sustentabilidade. Isto ocorreria, principalmente, pela redução do consumo da energia gasta com a distância do deslocamento e com a necessidade do uso do veículo particular, que contribuiriam para diminuição da poluição e o aumento da qualidade ambiental urbana. Potenciais características urbanas para a autonomia, no contexto do Planejamento da Paisagem, foram destacadas para a seleção de unidades de paisagem, previamente delimitadas na área urbana da cidade de Paranaguá. Quadros de correlação foram utilizados em duas etapas, para avaliar sete unidades de paisagem. Duas destas unidades apresentam potencialidade para se tornarem unidades urbanas com maior autonomia. Estas unidades possuem predomínio do uso residencial, concentração de serviços e facilidades em ruas específicas, pequena distância entre os pontos, elevada densidade demográfica e das edificações nos limites da qualidade ambiental urbana. Contudo, questões pertinentes ao transporte público, reuso de terrenos e edificações, mobilidade urbana e disponibilidade de equipamentos públicos precisam ser adequadas para se obter maior autonomia e seus benefícios.

PALAVRAS-CHAVE: Cidade Compacta. Planejamento da Paisagem. Unidades de paisagem.

\begin{abstract}
In literature there is an intense discussion about the advantages and disadvantages of increasing population density and buildings, that is, compaction, for the sustainability of urban areas. The Compact City theory indicates that the greater the autonomy of urban units, the greater is its sustainability. This would mainly be due to the reduction of the use of energy related to the distance of the displacement and the necessity of the use of the private vehicle, which would contribute to the reduction of pollution and increase the quality of the urban environment. Potential urban characteristics for autonomy, in the context of Landscape Planning, were highlighted for the selection of landscape units, previously delimited in the urban area of the municipality of Paranaguá. Correlation frames were used in two steps to evaluate seven landscape units. Two of these units have the potential to be becoming urban units with greater autonomy. These units have a predominance of residential use, the concentration of services and facilities in specific streets, short distances between points, high population density and buildings within the limits of urban environmental quality. However, issues related to public transport, re-use of land and buildings, urban mobility and the availability of public equipment, needs to be adequate for greater autonomy and benefits.
\end{abstract}

KEYWORDS: Compact City. Landscape Planning. Landscape units.

\title{
Resumen
}

En la literatura existe una intensa discusión sobre las ventajas y desventajas del aumento de la densidad poblacional y de las edificaciones, o sea, de la compactación, para la sostenibilidad de las áreas urbanas. La teoría de la Ciudad Compacta indica que cuanto mayor sea la autonomía de unidades urbanas, mayor será su sostenibilidad. Esto ocurrir, principalmente, por la reducción del uso de la energía relacionada con la distancia del desplazamiento y con la necesidad del uso del vehículo particular, que contribuirían a reducir la contaminación y el aumento de la calidad del ambiente urbano. Potenciales características urbanas para la autonomía, en el contexto de la Planificación del Paisaje, fueron destacadas para la selección de unidades de paisaje, previamente delimitadas en el área urbana del municipio de Paranaguá. Los cuadros de correlación se utilizaron en dos etapas, para evaluar siete unidades de paisaje. Dos de estas unidades presentan potencialidad para convertirse en unidades urbanas con mayor autonomía. Estas unidades poseen predominio del uso residencial, concentración de servicios y facilidades en calles específicas, distancia corta entre los puntos, alta densidad demográfica y de las edificaciones en los límites de la calidad ambiental urbana. Sin embargo, las cuestiones relacionadas con el transporte público, la reutilización de terrenos y edificaciones, la movilidad urbana y la disponibilidad de equipos públicos deben ser adecuadas para obtener mayor autonomía y sus beneficios.

PALABRAS CLAVE: Ciudad Compacta. Planificación del paisaje. Unidades de paisaje. 


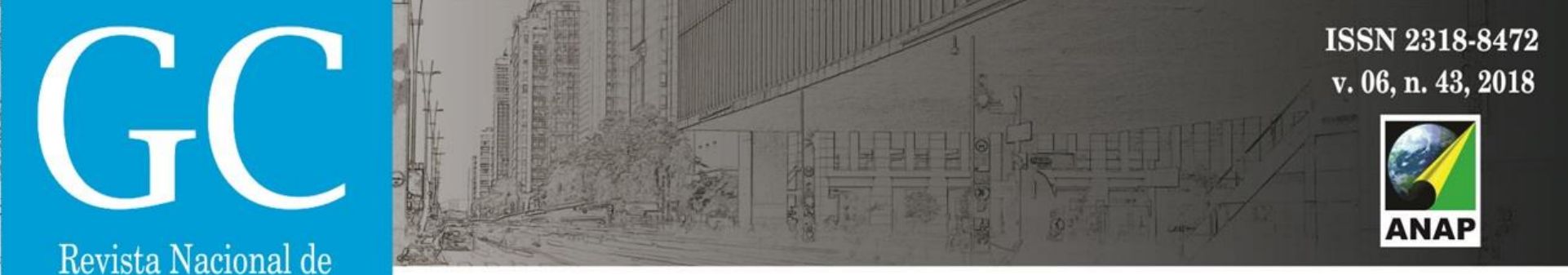

Revista Nacional de Gerenciamento de Cidades

\section{INTRODUÇÃO}

Nos países em desenvolvimento, no geral, os crescimentos do tipo vertical e horizontal, rápidos e descontrolados podem resultar no desenvolvimento de áreas urbanizadas sem planejamento, com infraestrutura urbana insuficiente, e ter alta população relativa com reduzida qualidade do meio ambiente em que tal população está inserida.

A literatura propõe que o crescimento urbano horizontal e contínuo aumenta a dificuldade do transporte e também sugere que a disposição da urbe pode dispor de uma configuração mais compacta e uma escala mais compatível para melhorar a eficiência e uso de alternativas de transporte de veículo individual como por exemplo o transporte público, a caminhada e o ciclismo.

A área urbanizada de Paranaguá, no litoral paranaense, está inserida em um local de florestas, manguezais e rios, na maior extensão contínua de Mata Atlântica do Brasil.

Historicamente o desenvolvimento populacional e da área urbana ocorreu de forma horizontal, rápida e espontânea (RICOBOM, 2012). Atualmente, o crescimento horizontal do município se apresenta de forma restrita. Assim, para o município atender novas moradias, existe uma alternativa viável no qual o crescimento se dá pela verticalização das edificações, conforme as orientações dispostas no Plano Diretor Municipal (PARANAGUÁ, 2007).

Levando em consideração os atributos do município e entendendo que o modelo de compactação urbana sugere influência direta sobre a qualidade ambiental da urbe, é fundamental que a proposta de concentração populacional por verticalização das edificações considere as propriedades ambientais na tomada de decisão.

Assim, pretende-se identificar os potenciais núcleos de bairros e evidenciar suas potencialidades para o adensamento demográfico descentralizado, de acordo com a Teoria da Cidade Compacta (CC) no contexto do Planejamento da Paisagem e da Qualidade Ambiental Urbana, para subsidiar teórico e metodologicamente o Planejamento Urbano do Município de Paranaguá.

\section{REFERENCIAL TEÓRICO}

O Planejamento da Paisagem é uma ferramenta de gestão que agrupa os princípios da ecologia na deliberação para planejar paisagens urbanas e rurais, considerando suas potencialidades (limites e aptidões), no uso e ocupação da terra, em escalas variadas, visando a qualidade ambiental, além de outras características para as necessidades humanas ( $\mathrm{NUCCl}, 2008 ; 2009$ ). Sendo, dessa forma, fundamental harmonizar a necessidade do uso da terra com a proteção ambiental, sendo necessário o diagnóstico e o prognóstico da paisagem como procedimentos práticos para superar esses desafios, durante esta análise (BARSCH et al., 2002). 
Para isto, o planejamento do desenvolvimento da localidade, baseado no regional, que se subordina ao planejamento nacional, tem que levar em conta as normativas para a prevenção, mitigação e compensação do impacto (WILKE, et al., 2002; HAAREN, et al., 2008).

O objetivo principal da teoria da Cidade Compacta é a retenção do crescimento urbano na direção horizontal, com a finalidade de elevar a compactação com o uso misto do solo (JENKS, BURTON; WILLIAMS, 1996).

Características essenciais do modelo de Cidade Compacta no contexto do Planejamento da Paisagem e da Qualidade Ambiental Urbana, estão sintetizados no QUADRO 1.

\section{QUADRO 1 - Demonstrativo resumido das características da teoria da Cidade Compacta no contexto do Planejamento da Paisagem e da Qualidade Ambiental Urbana.}

\begin{tabular}{|c|c|c|}
\hline CARACTERÍSTICA & VANTAGEM & RISCO \\
\hline Distância curta entre os pontos & $\begin{array}{l}\text { Menor uso de combustíveis, maior uso } \\
\text { da bicicleta e de caminhada }\end{array}$ & $\begin{array}{l}\text { Congestionamento e a consequente } \\
\text { poluição sonora e do ar }\end{array}$ \\
\hline $\begin{array}{l}\text { Núcleos de bairros - concentração dos } \\
\text { serviços e facilidades com baixo } \\
\text { potencial para causar poluição, em } \\
\text { certos locais (Centro de Bairros) } \\
\text { entorno dos quais se desenvolvem os } \\
\text { bairros residenciais. }\end{array}$ & $\begin{array}{l}\text { Oferta de empregos e facilidades que } \\
\text { estimulam o comércio a caminhada, o } \\
\text { uso da bicicleta e o lazer na localidade }\end{array}$ & $\begin{array}{l}\text { Perder o controle sobre a localização, a } \\
\text { intensidade e o tipo de uso nos núcleos } \\
\text { de bairros. }\end{array}$ \\
\hline $\begin{array}{l}\text { Alta densidade demográfica e } \\
\text { verticalização das edificações com } \\
\text { limite de pavimentos }\end{array}$ & $\begin{array}{l}\text { Não sobrecarrega a infraestrutura } \\
\text { urbana e viabiliza sua manutenção. } \\
\text { Vitalidade social e econômica. } \\
\text { Redução do uso de terras agrícolas e } \\
\text { de habitats naturais. }\end{array}$ & $\begin{array}{l}\text { Ultrapassar o limite da quantidade em } \\
\text { relação a qualidade com consequências } \\
\text { para o ambiente. }\end{array}$ \\
\hline $\begin{array}{l}\text { Foco no transporte público eficiente, } \\
\text { limpo, barato e frequente }\end{array}$ & $\begin{array}{l}\text { Menor uso do carro particular e de } \\
\text { suas consequências }\end{array}$ & $\begin{array}{l}\text { Não ocorrer a troca do automóvel } \\
\text { particular pelo transporte público. }\end{array}$ \\
\hline Concentração descentralizada & $\begin{array}{l}\text { Maior autonomia porque obtém-se } \\
\text { maior independência dos fatores } \\
\text { externos da localidade e maior } \\
\text { controle sobre as questões social, } \\
\text { econômica e ambiental }\end{array}$ & $\begin{array}{l}\text { Não alcançar a autonomia pelas } \\
\text { dificuldades inerentes ao processo. }\end{array}$ \\
\hline $\begin{array}{l}\text { Edificações planejadas para } 0 \\
\text { aproveitamento dos benefícios dos } \\
\text { recursos naturais }\end{array}$ & $\begin{array}{l}\text { Redução do consumo de energia pela } \\
\text { iluminação e pela ventilação natural, } \\
\text { maior conforto térmico, captação da } \\
\text { energia solar para aquecimento da } \\
\text { água e geração de energia elétrica. }\end{array}$ & \\
\hline $\begin{array}{l}\text { Reutilização de terrenos, edificações e } \\
\text { da infraestrutura previamente } \\
\text { desenvolvida }\end{array}$ & $\begin{array}{l}\text { Crescimento urbano até o limite físico } \\
\text { da localidade e redução das perdas } \\
\text { das áreas rurais }\end{array}$ & $\begin{array}{l}\text { Não respeitar os limites físicos da } \\
\text { localidade e utilizar os espaços livres de } \\
\text { edificação do local. }\end{array}$ \\
\hline
\end{tabular}

FONTE: Jenks, Burton, e Williams, 1996. Organização: os autores. 
Em relação aos pontos destacados, Pescatori $(2015$, p. 47) comenta que "objetivam conter a dispersão, focando a retração e a contenção do processo dispersivo por meio de planos, estratégias e inúmeros instrumentos urbanísticos e diretrizes de projeto."

Nesse contexto, resumindo, a proposta de Cidade Compacta apresentada, prevê a redução do consumo de energia por meio da redução dos trajetos com o automóvel individual. Essa redução ocorreria pelos seguintes motivos: aumento da disponibilidade de empregos nos centros de bairros pelo uso misto da terra; menor distância entre as habitações e as facilidades, serviços e lazer que favorecem o deslocamento a pé ou por bicicleta e/ou favorece viagens mais rápidas entre esses pontos; substituição do uso do carro pelo transporte público que deve ligar de forma eficiente os núcleos de bairros entre si e estes com centralidade municipal. Assim, os pontos em torno dos quais os bairros se desenvolvem são previstos pelos nós do transporte público.

Desta forma, o modelo da Cidade Compacta é composto por uma rede de bairros, cada um com sua autonomia, harmonizando uma diversidade de atividades particulares e públicas sobrepostas (PEBBU, 2008). Esse conceito tem sido denominado na literatura como concentração descentralizada, sendo uma configuração de ocupação do solo baseada em núcleos urbanos com altas densidades e relativamente próximos entre si de modo a permitir a acessibilidade e complementaridade funcional entre eles, conforme relata Santos (1998).

A dimensão destes núcleos varia conforme as características regionais, contudo deve incentivar maior eficiência no uso dos recursos naturais com o objetivo de melhorar a qualidade ambiental.

Importante ressalvar que no contexto abordado os "nós" de transporte público onde se concentram os serviços e as facilidades nas localidades significam os centros de bairros. A unidade constituída pelo centro de bairro e os bairros residenciais que se desenvolvem nas proximidades é denominada de núcleo de bairros. Assim, o conceito de uso misto da terra, neste trabalho, é explanado como a oferta de serviços e facilidades agrupados nos centros de bairros, próximos o suficiente das habitações, favorecendo o uso da bicicleta ou da caminhada para a prática das atividades cotidianas e satisfatoriamente afastadas evitando conflitos com o uso residencial.

Sendo assim, cada núcleo de bairro teria mais autonomia. Este termo, segundo Scoffham e Vale (1996), é o mais adequado para abranger o controle sobre as questões sociais, econômicas e ecológicas, cujo desenvolvimento representa maior independência dos fatores externos da localidade.

Entretanto, a energia economizada através dessa organização urbana pode ser considerada insignificante, visto que com frequência pode ocorrer engarrafamento, sendo então reduzida a otimização energética do combustível pelo aumento do tempo de trajeto e pela baixa velocidade do tráfego (THOMAS; COUSINS, 1996a).

Esta situação gera outras preocupações como a maior poluição sonora e atmosférica e também a perda dos benefícios provenientes da diminuição dos trajetos, que podem ser perdidos em função dos efeitos adversos do engarrafamento na rota dos veículos e nas 


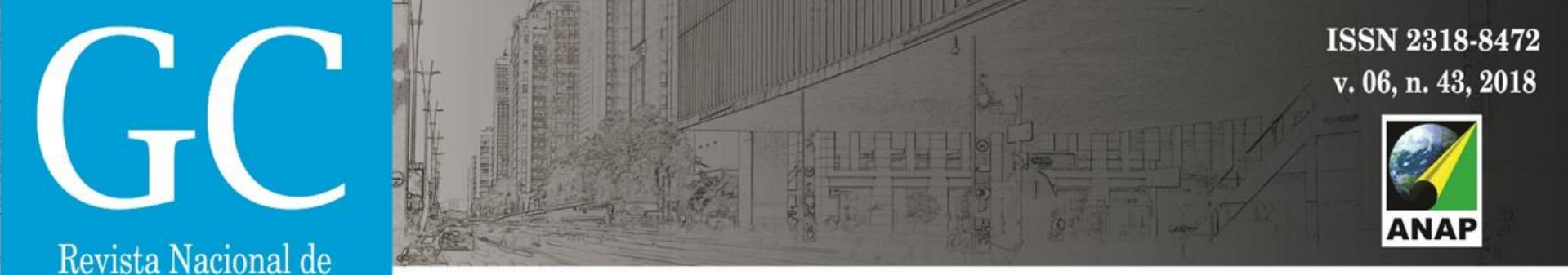

Revista Nacional de Gerenciamento de Cidades

condições de tráfego. Seus efeitos podem se concentrar nessas áreas, afetando adversamente as pessoas (BARRET, 1996; TONETTI; NUCCI; VALASKI, 2016). Neste contexto, Ní Rian et al (1996) esclarecem que a geometria de uma cidade influencia na determinação do clima, na escala e nas ruas desta cidade, tornando-se importante entender a relação entre a dispersão da poluição e a organização urbana.

Neste contexto, observa-se que a redução destes efeitos depende das ações que impulsionam a atratividade do transporte público (THOMAS; COUSINS, 1996a), tais como reduzir o uso do carro individual e aumentar o ciclismo e a caminhada.

Essa mudança tende a ocorrer com a promoção de condições adequadas para a caminhada e uso da bicicleta e com um transporte público eficiente, limpo e barato (JENKS; BURTON; WILLIAMS, 1996), sendo uma das diretrizes previstas na Política Nacional de Mobilidade Urbana (BRASIL, 2012), a qual prioriza o deslocamento a pé e com bicicleta em relação ao transporte coletivo e público e estes em relação ao uso do carro próprio.

A promoção das vantagens no modelo de Cidade Compacta depende da programação e controle do uso misto da terra nos núcleos de bairros. Sendo assim, a disposição de usos com elevado potencial de causar poluição e/ou de grande número de usos com baixo potencial para causar poluição que no conjunto afetam a qualidade ambiental, não devem compor os centros de bairros, sob o risco de redução da qualidade ambiental, ainda que isso seja justificado pelo aumento do número de empregos locais. Tais usos devem estar afastados dos centros urbanos/residenciais como forma de minimização do risco que estes usos possam a vir causar, conforme relatam Gouvêa e Tonetti (2017).

Fulford (1996) explica que a garantia da qualidade ambiental necessária para sobrevivência humana é dependente de um controle contínuo sobre o local, o tipo e a intensidade dos usos potencialmente poluidores, assim como sobre o número de habitantes por hectare, sendo frequentemente convencionado por organizações como Friends of the Earth que uma rede residencial de densidade com cerca de 300 hab/ha seja potencialmente sustentável. 0 padrão aceito pela Associação Norte-Americana de Saúde Pública é 312,5 hab/ha, conforme menciona Nucci (2008). Na mesma página, o autor apresenta uma relação entre a densidade populacional versus os custos de infraestrutura, demonstrando que os limites interessantes financeiramente estão entre 200 e 450 hab/ha, onde o custo de manutenção da infraestrutura fica oneroso acima de 450 e abaixo de 200 hab/ha.

Acredita-se que no modelo de cidade compacta existe a possibilidade de balancear a densidade de habitações/populacional e os empregos e reduzir o número de viagens diárias, diminuindo os custos dos empregos e aumentando o tempo de lazer da população (THOMAS; COUSINS, 1996b). Também, as pesquisas comprovam que o Núcleo de Bairro, também determinado como concentração descentralizada, tem capacidade de fornecer um modelo de desenvolvimento cujas demandas ambiental, social e econômica podem ser atendidas, alcançando-se o apoio público (THOMAS; COUSINS, 1996b). 


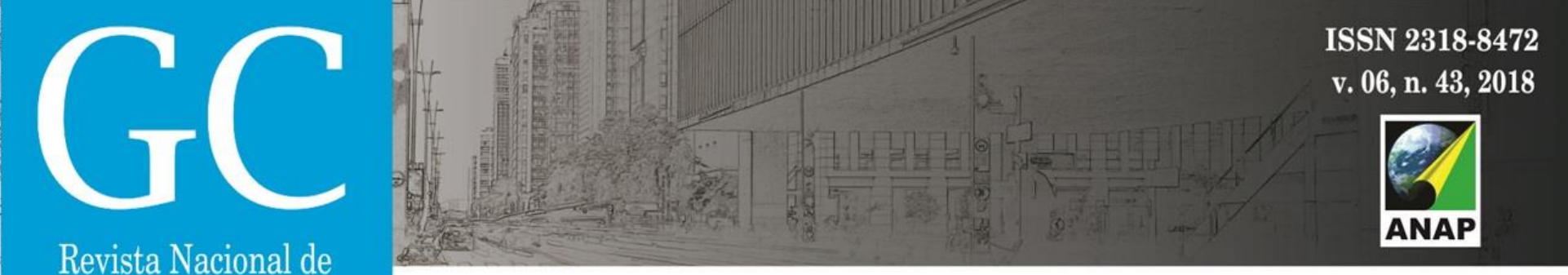

Revista Nacional de Gerenciamento de Cidades

A compactação urbana não exige obrigatoriamente a aplicação do modelo de blocos de edifícios, o qual atribui efeitos negativos que podem ser atrelados a esse tipo de construção, conforme os que foram descritos por Nucci et al. (2008) ao afirmar que além de quatro pisos os proveitos com espaços livres de edificações são proporcionalmente menores do que os proveitos com a altura, não compensando os impactos ambientais decorrentes do aumento demográfico e da intensificação do uso do solo gerando danos ao meio ambiente, especialmente no ar, no solo e na água. Para controlar o consumo de energia, a cidade de Dongtan na China, limitou um máximo de seis pavimentos as edificações da cidade (PLANETA SUSTENTÁVEL, 2008).

Outro benefício proveniente da compactação urbana é a redução ou minimização da pressão de ocupação dos espaços rurais, pela redução do crescimento horizontal. Observando o fato que as cidades transferem um enorme peso para o campo, pois demandam terra, água, agregam construções e produzem muitos resíduos (BURTON; MATSON, 1996), caracterizando um modelo que provoca as grandes perdas das terras agrícolas e dos habitats naturais (HILLMAN, 1996). Causando a prejuízo de espécies nativas diretamente pelo crescimento das áreas urbanizadas e indiretamente pela modificação do habitat, pela poluição e pela competição com espécies exóticas que convivem no meio urbano (FULFORD, 1996).

Tonetti (2011) comenta que uma relação desses exemplos de cidades consideradas compactas pode ser feita com o modelo de concentração urbana frequentemente encontrada nos centros urbanos das metrópoles. A elevada densidade populacional não determina que tais centros urbanos sejam considerados exemplos de compactação conforme prediz a teoria da Cidade Compacta, abordado neste texto. Os centros metropolitanos mesmo tendo elevada densidade demográfica, proporcionam menores distâncias entre os pontos, maior oferta de empregos e atividades culturais, têm atributos que os distinguem da teoria abordada, tais como:

(1) possuem edificações com número grande de pisos que exigem alto consumo de energia sobrecarregando a infraestrutura urbana disponibilizada, gerando a intensificação do uso e ocupação do solo com impactos negativos na água, no solo e no ar;

(2) apresentam ineficiência no uso sustentável do automóvel individual ou coletivo devido aos frequentes congestionamentos e consequentemente demandam alto consumo de energia, gerando alto risco de poluição sonora e atmosférica;

(3) as calçadas comumente são estreitas desprovidas de segurança e não há ciclovias ou ciclo faixas, o que dificulta a troca do automóvel pela caminhada ou pela bicicleta, assim como não incentiva a interação social;

(4) a presença de espaços de uso público livres de edificações como por exemplo praças ou academias ao ar livre é frequentemente reduzida ou de péssima qualidade por causa do estado de conservação ou devido à proximidade a ruas com tráfego intenso de veículos, o que caracteriza déficit desses tipos de espaços; 


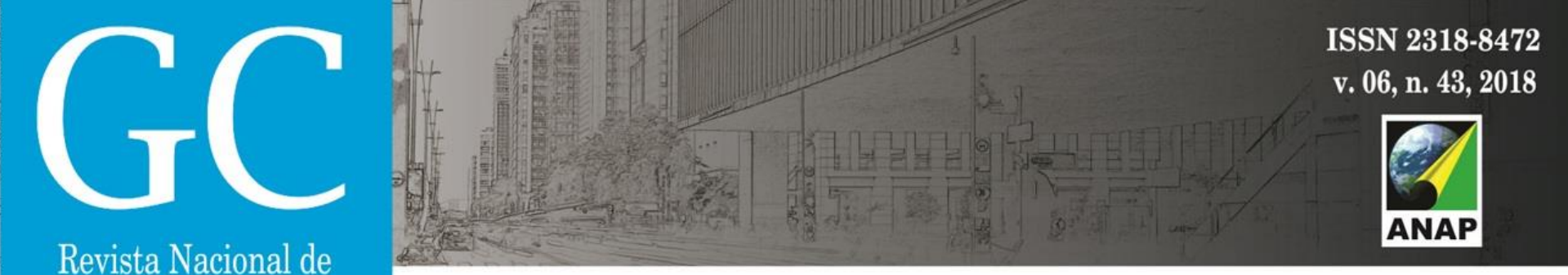

Gerenciamento de Cidades

(5) a presença da vegetação e arborização é pouca ou inexistente; apesar de toda essa verticalização das áreas centrais, o crescimento horizontal nos subúrbios continua expandindose e consumindo os habitats rurais.

No conjunto, essas características constituem locais com reduzida qualidade ambiental, que evidencia a ausência de preocupação e controle com as questões do meio físico.

Seguindo esta linha de raciocínio, Willians, Burton e Jenks (1996) sintetizam o modelo ao comentarem que a ativação das regiões urbanas pode promover maior segurança e harmonia social e sobretudo, ser socialmente igualitárias, já que os serviços e facilidades podem ser acessados naturalmente por qualquer pessoa, com ou sem automóvel. Esta promoção só é possível a partir de certa densidade populacional na Cidade Compacta. Assim, prover essa acessibilidade é componente chave do planejamento urbano na Cidade Compacta para a qualidade ambiental (WILLIANS; BURTON; JENKS, 1996) ou, simplesmente, o componente necessário para a ampliação das formas urbanas mais sustentáveis (THOMAS; COUSINS, 1996b).

\section{METODOLOGIA}

Foram organizadas planilhas específicas dos dados dos elementos da paisagem e das Unidades de Paisagens (UP) geradas para a elaboração do estudo de Tonetti (2011) presentes na base de dados do referido autor, para estabelecer correlações (MONTEIRO, 2000) para verificar a potencialidade de cada UP atuar como um Núcleo de Bairro.

A descrição dos protocolos para a coleta de dados para preenchimento do quadro de correlações para verificar os potenciais Núcleos de Bairro dentre as UPs consideradas, são descritos a seguir:

1 - Bairro com uso residencial predominante - Os dados sobre o uso do solo nas UPs foram obtidos do quadro de correlações do trabalho de Tonetti (2011, p. 194). Estes, estão expressos em porcentagem do uso em relação ao total da área ocupada da UP;

2 - Aparente/visualmente concentração de serviços em ruas específicas ou Presença de ruas com serviços e facilidades (Centros de Bairros) em visitas in loco e a partir da visualização da carta temática de uso do solo do trabalho de Tonetti $(2011$, p. 155) onde pode ser verificada a possível concentração dos usos relacionados a serviços e facilidades em ruas das UPs;

3 - Distância curta entre os pontos - tomando como base a citação de Barton e Tsourou (2000) de que até $800 \mathrm{~m}$ equivalente a $10 \mathrm{~min}$. de caminhada é uma medida que não desmotiva o pedestre no deslocamento. Esta medida será usada como referência no interior da UP para a distância das residências ao centro de bairro, aos espaços de lazer, escolas, etc;

4 - Alta densidade demográfica no limite da QAU - foi utilizado o mapa no 4 de densidade demográfica do Plano Diretor de Desenvolvimento Integrado de Paranaguá (PARANAGUÁ, 2007) com as classes de densidade contidas nele;

5 - Verticalização das edificações no limite da QAU - a partir da visualização da carta temática das edificações com mais de quatro pavimentos no local de estudo de Tonetti (2011, p. 166); 


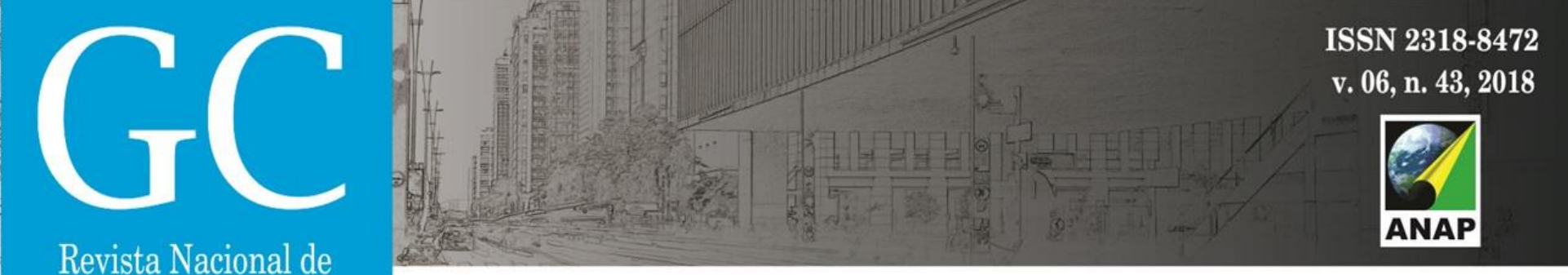

Gerenciamento de Cidades

6 - Presença de transporte público eficiente (frequente) e confortável, ligando o NB ao centro e a outros NB - o levantamento desses dados foi realizado durante as visitas in loco de forma qualitativa mediante observação da frequência, da lotação e do aparente estado de limpeza e conforto dos ônibus que conectam as UPs entre si e com a centralidade.

7 - Reutilização de terrenos e/ou edificações existentes - avaliação visual dos lotes e dos imóveis em relação ao uso original e ao atual em relação aos princípios do Planejamento da Paisagem.

Cabe destacar que a UP Ila não foi avaliada por tratar-se da Unidade Central (Centro Municipal).

Posteriormente, foram, verificadas as características de cada Núcleo de Bairro em relação a sua potencialidade para a autonomia em relação aos demais núcleos e em relação ao centro do município, também utilizando a metodologia de correlação proposta por Monteiro (2000), gerando um novo quadro de correlações. Este quadro de correlações foi preenchido mediante avaliação visual qualitativa da presença de facilidades e serviços em qualidade e quantidade para atendimento da população das UPs selecionadas no primeiro quadro de correlações.

Nessa linha teórica, os termos paisagem e unidade de paisagem seguem as definições atribuídas e discutidas por Monteiro (2000).

Neste texto, seguindo o exposto por Tonetti (2011) considera-se crescimento horizontal como sendo o tipo de desenvolvimento da área urbanizada que ocorre na direção horizontal, expandindo-se por sobre a área periférica e rural. Nessa mesma linha, o crescimento vertical é aquele que se desenvolve na direção vertical (tanto para cima quanto para baixo) das edificações e grandes estruturas com aumento do volume construído e, geralmente, com ampliação da densidade demográfica.

\section{RESULTADOS E DISCUSSÃO}

As correlações observadas no quadro 2 evidenciam que duas das UPs consideradas possuem potencialidade para atuarem como Núcleos de Bairros por preencherem cinco dos sete critérios estabelecidos para essa verificação a partir da literatura específica consultada, diante da metodologia do quadro de correlações, conforme critérios estabelecidos com base na teoria da Cidade Compacta, apresentados por Jenks, Burton e Williams (1996). 
Quadro 2: Quadro de correlações da potencialidade dos Núcleos de Bairro do local de estudo.

\begin{tabular}{|l|l|l|l|l|l|l|l|}
\hline $\begin{array}{l}\text { CARACTERÍSTICAS DOS NÚCLEOS DE } \\
\text { BAIRRO }\end{array}$ & UP I & UP IIb & UP IIIa & UP IIIb & UP IIIc & UP IVa & UP IVb \\
\hline $\begin{array}{l}\text { Bairro com predomínio do uso } \\
\text { residencial em \% }\end{array}$ & 9,4 & 20 & 35,2 & 24 & 35,4 & 43,1 & 56,1 \\
\hline $\begin{array}{l}\text { Concentração de serviços e facilidades } \\
\text { em ruas específicas (Centros de Bairros) }\end{array}$ & não & não & não & não & não & Sim & Sim \\
\hline Distância curta entre os pontos & não & não & sim & sim & sim & sim & sim \\
\hline $\begin{array}{l}\text { Alta densidade demográfica no limite } \\
\text { da QAU (até 400 hab/ha) }\end{array}$ & $\begin{array}{l}151- \\
200\end{array}$ & $02-50$ & $\begin{array}{l}200- \\
250\end{array}$ & $\begin{array}{l}101- \\
150\end{array}$ & $\begin{array}{l}151- \\
200\end{array}$ & $201-$ & 250 \\
\hline $\begin{array}{l}\text { Verticalização das edificações no limite } \\
\text { da QAU (mais de 4 pavimentos) }\end{array}$ & 0 & 0 & 0 & 0 & 0 & 8 & 0 \\
\hline $\begin{array}{l}\text { Presença de transporte público } \\
\text { eficiente }\end{array}$ & não & não & não & não & não & não & não \\
\hline $\begin{array}{l}\text { Reutilização de terrenos e/ou } \\
\text { edificações existentes }\end{array}$ & não & não & não & não & não & não & não \\
\hline
\end{tabular}

Fonte: os autores.

Verifica-se que em ambas as UPs evidenciadas no quadro 2, há predominância do uso residencial, facilidades e serviços concentrados nas vias de tráfego prioritárias, a densidade demográfica está abaixo do limite superior considerado e o número e a distribuição das edificações com mais de quatro pavimentos não é elevado e possivelmente não comprometem a QAU no local. Contudo, o transporte público eficiente e a reutilização das edificações existentes, são aspectos que precisam ser melhorados como tentativa para diminuir o uso do veículo individual e o elevação do gasto energético com a demolição e construção de novas edificações.

As observações evidenciaram a ineficiência do transporte nestas UPs, após as visitas in loco, verificou-se a falta de regularidade nos horários dos ônibus, desconforto do passageiro em relação a lotação excessiva, ruído, e temperaturas elevadas no interior do veículo. Desta forma, as referidas Unidades de Paisagem, também não atenderam ao critério facilidade de descolamento com a área central do município, por questões relacionadas ao tempo e ao uso do veículo individual e a dificuldade de acesso, principalmente em horários de muito movimento.

A principal vantagem do agrupamento descentralizado é a habilidade para diminuir a dependência do uso do automóvel e do consumo de combustíveis, por meio da compactação e de centros periféricos com caminhos de transporte público eficientes na utilização da energia (THOMAS; COUSINS, 1996a).

Desta forma, esses potenciais NB, apesar de apresentarem características favoráveis, necessitam melhorar o transporte público para poderem atingir os benefícios ambientais que a redução do uso do automóvel e dos congestionamentos proporcionam no ambiente local.

O seguinte quadro de correlações (Quadro 3), mostra os critérios para verificar se os potenciais Núcleos de Bairros selecionados tem potencial para a concentração descentralizada ou seja para maior autonomia o que equivale a maior independência dos fatores externos da localidade e maior controle sobre as questões ambientais, focadas neste trabalho. 
Quadro 3: Quadro de correlações da potencialidade da Concentração Descentralizada dos potenciais Núcleos de Bairro, do local de estudo.

\begin{tabular}{|l|l|l|}
\hline Critérios para verificar a potencialidade da Concentração Descentralizada & UP IVa & UP IVa \\
\hline Potencialidade da Oferta de empregos & Sim & Sim \\
\hline $\begin{array}{l}\text { Serviços bancários - agências ou unidades que atuem como agências: lotéricas por } \\
\text { exemplo }\end{array}$ & Sim & Sim \\
\hline Prefeitura - unidade de atendimento/pagamento de taxas & Não & Não \\
\hline Correios & Sim & Sim \\
\hline Posto de saúde & Não & Não \\
\hline Supermercado & Sim & Sim \\
\hline Farmácia & Sim & Sim \\
\hline EUPLEs - Áreas de lazer - para crianças, jovens e adultos & Não & Não \\
\hline Unidades de ensino & Não & Não \\
\hline $\begin{array}{l}\text { Presença de equipamentos e/ou edificações planejados para aproveitar os recursos } \\
\text { naturais }\end{array}$ & Não & Não \\
\hline Alta qualidade das calçadas & & Não \\
\hline Alta qualidade das ciclovias & Não & Não \\
\hline
\end{tabular}

Fonte: os autores.

Evidencia-se no quadro acima, que dos doze itens selecionados, sete não foram considerados satisfatórios nos potenciais núcleos de bairro. Os itens considerados insatisfatórios estão diretamente relacionados com a gestão pública. Neste caso, existem deficiências de unidades de saúde, ensino e lazer. Também, a gestão pública é responsável pelo planejamento e fiscalização para a implementação e manutenção das calçadas e ciclovias com alta qualidade nas referidas UPs.

Assim, considera-se que as duas UPs selecionadas no quadro 2, apesar de apresentarem aspectos potenciais de Núcleos de Bairros, não possuem autonomia ou independência suficiente (Concentração Descentralizada) do centro ou das outras UPs, principalmente em relação aos itens relacionados com a gestão pública.

Desta forma, cabe a gestão pública o direcionamento do planejamento e implementação da infraestrutura pública em quantidade e qualidade adequada, nos referidos locais para promover a autonomia, para a obtenção dos benefícios que ela proporciona ao ambiente, principalmente em relação a promoção do deslocamento não motorizado para a realização das atividades cotidianas e do lazer, que, hoje, estão direcionadas para o uso carro particular, em função da baixa qualidade e da alta distância da residência. Sendo este aspecto fundamental para a obtenção dos benefícios ambientais na Cidade Compacta.

Neste sentido, esses potenciais núcleos de bairros, apesar de apresentarem certas características para a independência das demais localidades, não podem ser considerados autônomos.

Na organização dos núcleos de bairros, a conexão da residência com a promoção de serviços e facilidades é uma das formas de diminuir a demanda por trajetos de automóvel particular e motivar a caminhada e o ciclismo que são formas de deslocamentos mais sustentáveis.

Deve-se também levar em consideração os trajetos com outros objetivos que não o trabalho para tais facilidades (FARTHING; WINTER; COOMBES, 1996). Scoffham e Vale (1996) reforçam essa ideia afirmando que uma caminhada de no máximo 10 minutos da residência mais afastada até a escola ou ponto de transporte público mais distante em um modelo de vizinhança interativa com um conjunto de facilidades locais como escolas, espaços para 
diversões, mercados e até indústrias "limpas", fortalecem uma aceitação maior para este tipo de caminhada.

Pelo exposto, introduz Troy (1996) uma solução para a soma da energia gasta pelo deslocamento seria ajustar a necessidade pela realocação dos destinos, desenvolvendo conjuntos de centros de bairros conectados por um sistema de transporte público (não necessariamente o trem). Afirma ainda que, a descentralização dos comércios no varejo e a administração pública podem precisar do vínculo de uma política que garanta o investimento na cultura e nas facilidades de lazer que deveriam ser desenvolvidas individualmente nos centros (TROY, 1996).

Troy (1996) ressalta ainda que os moradores locais podem satisfazer suas necessidades de deslocamento através da disposição da distribuição de seus destinos finais e também podem ter variada escolha nos empregos oferecidos, comércio, cultura e atividades de lazer exatamente no local onde vivem, tendo menor necessidade para viajar.

A redução do gasto de energia pelo uso misto do solo e deslocamento dos pontos finais das viagens geram ganhos, porém não justificam a implantação de usos potencialmente poluidores, assim como as consequências do agrupamento de usos específicos cuja capacidade de causar poluição seja menor.

\section{CONSIDERAÇÕES FINAIS}

Pode-se garantir que existe a potencialidade para que duas UPs em Paranaguá possam atuar como Núcleos de Bairros de acordo com a teoria da Cidade Compacta utilizada neste trabalho. Contudo, medidas precisam ser implementadas para que essas unidades de paisagem possam atuar como verdadeiros Núcleos de Bairro, com autonomia em relação ao centro e a outros Núcleos de Bairro, para obter as benfeitorias da melhoria da qualidade ambiental urbana que essa organização urbana pode oferecer aos moradores.

Observações preliminares indicam que outras localidades no município também apresentam essa potencialidade. Assim, novas pesquisas necessitam ser realizadas para verificar a teia de relações entre os potenciais Núcleos de Bairros presentes em toda a área urbanizada de Paranaguá para pensar e planejar melhor as ações para promover a autonomia/independência dessas localidades para otimizar os ganhos ambientais com a melhoria da qualidade do ambiente que isso pode proporcionar.

A metodologia utilizada aqui é simples e de baixo custo podendo ser aplicada facilmente em campo por estudantes ou pelos responsáveis públicos para pensar o planejamento urbano de Paranaguá.

A adoção de políticas públicas conduzirá as áreas urbanas existentes ao padrão de compactação desejado na implantação da Cidade Compacta, a qual necessita de uma proposta de desenvolvimento urbano aceita e apoiada pela comunidade local. Para que essa proposta seja executada, precisa motivar os novos moradores, garantindo os benefícios e garantindo que a mudança não acarretará prejuízos com o engarrafamento e superlotação.

A compactação urbana pode beneficiar a população com a redução das perdas dos espaços rurais e de habitats naturais importantes como por exemplo parques e passeios, através do retardo do crescimento da área urbana por transformar o uso do solo mais efetivo. Durante a implantação do modelo deve-se priorizar os espaços de uso público e livres de edificações do meio urbano, com o objetivo de não perder estas áreas durante a compactação. 
Essa condição é essencial no município de Paranaguá cuja situação geográfica e jurídico ambiental impedem o crescimento horizontal e este por sua vez dificulta a promoção de infraestrutura urbana em quantidade e qualidade adequadas para os bairros mais afastados. A implantação do modelo de blocos de edifícios não deve ser considerada a única configuração de compactação do ambiente urbano nem a que beneficia maiores ganhos ecológicos, visto que o uso e ocupação intensos do solo com impactos negativos no consumo de água, uso do solo e poluição atmosférica.

A literatura apresenta alguns exemplos de sucesso sobre a implantação da compactação urbana que se enquadram no modelo da Cidade Compacta. Nestes exemplos, o sucesso é fruto da dedicada organização da gestão local e de seus programas cuja participação da comunidade é de alto nível.

Neste sentido, recomenda-se a Cidade Compacta para atingir o equilíbrio entre a quantidade de habitantes e a qualidade do ambiente em que eles convivem. Porém, observa-se que novas pesquisas são necessárias, pois muito da teoria precisa de validação empírica, conforme abordado por SHERLOCK (1996), cuja descrição da Cidade Compacta expõe que a peça principal da tentativa de originar um meio urbano mais sustentável e ainda podendo tornar-se um local atrativo para se viver e trabalhar. Para que esse objetivo seja atingido, é indispensável a capacidade de promover uma concentração populacional equilibrada e variedade de atividades, sendo também necessário transformar as residências e as ruas em locais social e ambientalmente mais "amigáveis" e haver menor dependência do carro privado.

\section{REFERÊNCIAS BIBLIOGRÁFICAS}

BARSCH, H.; BASTIAN, O.; BEIERKUHNLEIN, C.; BOSSHARD, A.; BREUSTE, J.; KLÖTZLI, F.; OTT, K.; TRESS, B.; TRESS, G.; WEILAND, U. Application of landscape ecology. In: BASTIAN, O; STEINHARDT, U. Development and perspectives of landscape ecology. Dordrecht: Kluwer Academic Publishers, 2002, p. 307-431.

BARRET, G. The transport dimension. In: JENKS, M.; BURTON, E. e WILLIAMS, K. The Compact City: A Sustainable Urban Form? London: E \& FN SPON, 1996. 350p. p. 171- 180.

BARTON, H.; TSOUROU, C. Health urban planning. A WHO guide to planning for people. Londres: Spon Press (em nome da Organização Mundial da Saúde - WHO, 2000, 184p.

BRASIL. Lei 12.587 de 03 de janeiro de 2012. Institui a Política Nacional de Mobilidade Urbana. DOU de 04 jan. 2012. Disponível em <http://www.planalto.gov.br/ccivil_03/_ato2011-2014/2012/lei/l12587.htm> Acesso em 12 março 2017.

BURTON, T.; MATSON, L. Urban footprints: making Best use of urban land and resources - a rural perspective. In: JENKS, M.; BURTON, E. e WILLIAMS, K. The Compact City: A Sustainable Urban Form? London: E \& FN SPON, 1996. 350p. p. 298-291.

FARTHING, S.; WINTER, J.; COOMBES, T. Travel behaviour and local accessibility to services and facilities. In: JENKS, M.; BURTON, E.; WILLIAMS, K. The Compact City: A Sustainable Urban Form? London: E \& FN SPON, 1996. 350p. p. 181-189. FELLENBERG, G. Introdução aos problemas da poluição ambiental. São Paulo, EPU/SPRINGER/EDUSP, 1980. $196 \mathrm{p}$.

FULFORD, C. The compact city and the market: the case of residential development. In: JENKS, M.; BURTON, E.; WILLIAMS, K. The Compact City: A Sustainable Urban Form? London: E \& FN SPON, 1996. 350p. p. 122-133. 
GOUVÊA, P. M.; TONETTI, E. L.. Avaliação dos riscos de incêndio e explosão na área urbana de Paranaguá-PR. Revista Geografar: Curitiba, v. 12, n. 2, p. 233 - 250, jul. a dez./2017. Disponível em:

https://revistas.ufpr.br/geografar/article/view/52553/34764. Acesso em: 25 jul. 2018.

HAAREN, C. V.; GALLER, C.; OTT, S.. Landscape planning: the basis of sustainable landscape development. BfN Bundesamt für Naturschutz/ Federal Agency for Nature Conservation, Leipzig, 2008, 52p.

HILLMAN, M. In favor of the compact city. In: JENKS, M.; BURTON, E. WILLIAMS, K. The Compact City: A Sustainable Urban Form? London: E \& FN SPON, 1996. 350p. p. 36-44.

JENKS, M.; BURTON, E.; WILLIAMS, K. The Compact City: A Sustainable Urban Form. London: E \& FN SPON, 1996. $350 \mathrm{p}$.

MONTEIRO, C. A. F.. Geossistemas: a História de uma Procura. São Paulo: Contexto, 2000. 127p.

NÍ RIAN, C.; CROXFORD, B.; LITTLEER, J.; PENN, A. City space and pollution: a modeling and monitoring exercise. In: JENKS, M.; BURTON, E. e WILLIAMS, K. The Compact City: A Sustainable Urban Form? London: E \& FN SPON, 1996. 350p. p. 259-272.

NUCCI, J. C. Qualidade Ambiental e Adensamento Urbano: um estudo de ecologia e planejamento da paisagem aplicado ao distrito de Santa Cecília (MSP). Curitiba: Edição do autor (ISBN 978-85-908251-0-4), 2008 (2. ed.). 142p. Disponível em www.geografia.ufpr.br/laboratorios/labs/?pg=publicacoes-php Acesso em 15 dezembro 2008.

NUCCI, J. C. Ecologia e planejamento da paisagem. In: Douglas Gomes dos Santos; João Carlos Nucci. (Org.). Paisagens Geográficas. Um tributo a Felisberto Cavalheiro. Campo Mourão: FECILCAM, 2009, p. 50 - 64. Disponível em http://www.fecilcam.br/editora/index.php?option=com content\&task=blogcategory\&id=6\&ltemid=12 Acesso em 28 abril 2010.

PARANAGUÁ. Lei Complementar no 60, de 23 de agosto de 2007. Institui o Plano Diretor de Desenvolvimento Integrado no Município de Paranaguá. Disponível em:

http://www.paranagua.pr.gov.br/plano_diretor/PAG_INICIAL_Plano\%20Diretor\%20Leis/LEIS\%20DO\%20PLANO\%20 DIRETOR/PDF/LEI_COMPLEMENTAR_N060-PLANO_DIRETOR\%20Compilado.pdf. Acesso em: 07 set. 2018.

PEBBU - Performance Based Build. Compact city. 2008. Disponível em:

www.rdg.ac.uk/PeBBu/state_of_art/urban_approaches/compact_city/compact_city.htm Acesso em: 07 set. 2018.

PESCATORI, C. Cidade compacta e cidade dispersa: ponderações sobre o projeto do Alphaville Brasília. R. B. Estudos Urbanos e Regionais. V. 17, n. 2, p. 40 - 62, Ago. 2015. DOI. 10.22296/2317-1529.2015v17n2p40. Disponível em:< http://rbeur.anpur.org.br/rbeur/article/view/4995/4689 > Acesso em: 04 set. 2018.

PLANETA SUSTENTÁVEL. Cidade dos sonhos. Disponível em: www.planetasustentavel.abril.com.br . Acesso em: 06 maio 2018.

SANTOS, Á. Povoamento disperso e qualidade ambiental: uma abordagem relacional. Estatísticas e Estudos Regionais, 1998. Disponível em www.ine.pt/ngt server/attachfileu.jsp?look parentBoui=106754\&att display=n\&att download=y Acesso em: 19 dez. 2008.

SCOFFHAM, E.; VALE, B. How compact is sustentainable - How sustainable is compact? In: JENKS, M.; BURTON, E. e WILLIAMS, K. The Compact City: A Sustainable Urban Form? London: E \& FN SPON, 1996. p. 66-73.

RICOBOM, A. E. Metodologia auxiliar para a revisão de planos diretores municipais através da aplicação da cartografia prospectiva. Estudo de caso - perímetro urbano de Paranaguá. 511f. Tese (Doutorado) - Setor de Ciências da Terra, Universidade Federal do Paraná, Curitiba. 2012. Disponível em: https://acervodigital.ufpr.br/handle/1884/28555. Acesso em: 11 set. 2018. 


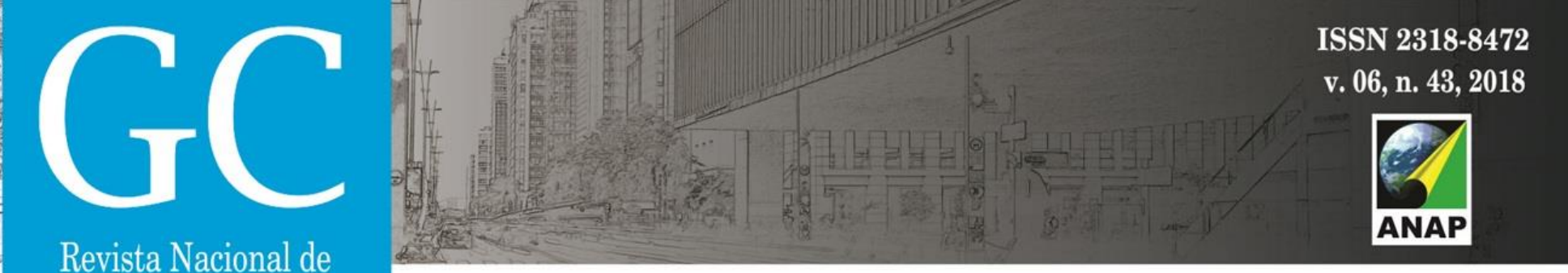

Gerenciamento de Cidades

National Journal of Cities Management

THOMAS, L.; COUSINS, W. The compact city: a successful, desirable and achievable urban form? In: JENKS, M.; BURTON, E. e WILLIAMS, K. The Compact City: A Sustainable Urban Form? London: E \& FN SPON, 1996a. p. 53-65.

THOMAS, L.; COUSINS, W. A new compact city form: concepts in practice. In: JENKS, M.; BURTON, E. e WILLIAMS, K. The Compact City: A Sustainable Urban Form? London: E \& FN SPON, 1996b. p. 328-338.

TONETTI, E. L. Potencialidades de adensamento populacional por verticalização das edificações e qualidade ambiental urbana no município de Paranaguá, Paraná, Brasil. 235f. Tese (Doutorado) - Setor de Ciências da Terra, Universidade Federal do Paraná, Curitiba. 2011. Disponível em:

http://200.17.203.155/index.php?codigo_sophia=285569. Acesso em: 07 set. 2018.

TONETTI, E.L.; NUCCI, J.C.; VALASKI, S. Espacialização de áreas potencialmente poluídas: proximidade de usos incompatíveis no município de Paranaguá-PR. Revista Nacional de Gerenciamento de Cidades, v. 04, n. 25, 2016, p. 33-50. Disponível em:

http://www.amigosdanatureza.org.br/publicacoes/index.php/gerenciamento_de_cidades/issue/view/131. Acesso em: 07 set. 2018.

TROY, P. N. Environmental stress and urban policy. In: JENKS, M.; BURTON, E. e WILLIAMS, K. The Compact City: A Sustainable Urban Form? London: E \& FN SPON, 1996. 350p. p. 200-212.

SHERLOCK, H. Repairing our much abused cities: the way to sustainable living. In: JENKS, M.; BURTON, E. e WILLIAMS, K. The Compact City: A Sustainable Urban Form? London: E \& FN SPON, 1996. 350p. p. 289-297.

WILKE, T.; SCHILLER, J.; KÖNZER, M.. Landscape planning for sustainable municipal development. BfN - Bundesamt für Naturschutz/ Federal Agency for Nature Conservation, Leipzig, 2002, 24p.

WILLIANS, K.; BURTON, E.; JENKS, M. Achieving the compact city through intensification: an acceptable option? In: JENKS, M.; BURTON, E.; WILLIAMS, K. The Compact City: A Sustainable Urban Form? London: E \& FN SPON, 1996. p. $83-96$. 